\title{
CRESCIMENTO DE MUDAS DE AÇOITA-CAVALO (Luehea divaricata Mart.) SOB INFLUÊNCIA DE DIFERENTES SUBSTRATOS E RECIPIENTES, EM VIVEIRO
}

Roselene Marostega Felker ${ }^{1}$; Suelen Carpenedo Aimi ${ }^{2}$; Maureen de Moraes Stefanello ${ }^{3}$; Eliara Marin Piazza ${ }^{4}$ Paulo Henrique Jung ${ }^{5}$

'Doutoranda do Programa de Pós Graduação em Engenharia Florestal, Universidade de Santa Maria - UFSM, Santa Maria, Brasil

Email: rosifelker@yahoo.com.br

${ }^{2}$ Doutoranda do Programa de Pós Graduação em Engenharia Florestal,

Universidade de Santa Maria - UFSM, Santa Maria, Brasil

${ }^{3}$ Mestranda do Programa de Pós Graduação em Engenharia Agrícola, Universidade Federal de Santa Maria - UFSM, Santa Maria, Brasil

${ }^{4}$ Doutoranda do Programa de Pós Graduação em Engenharia Florestal, Universidade Federal de Santa Maria - UFSM, Santa Maria, Brasil

${ }^{5}$ Mestrando do Programa de Pós Graduação em Engenharia Florestal, Universidade Federal de Santa Maria - UFSM, Santa Maria, Brasil

Recebido em: 08/09/2015 - Aprovado em: 14/11/2015 - Publicado em: 01/12/2015 DOI: http://dx.doi.org/10.18677/Enciclopedia_Biosfera_2015_120

\begin{abstract}
RESUMO
Luehea divaricata é uma espécie nativa de ampla distribuição no território brasileiro, muito utilizada como planta medicinal e em programas de reflorestamentos. Com a finalidade de fornecer mudas de qualidades para estes projetos, a presente pesquisa objetivou estudar o desenvolvimento da Luehea divaricata em diferentes substratos e recipientes. Foram coletadas sementes de árvores matrizes no município de Silveira Martins, e o experimento conduzido em casa de vegetação na Universidade Federal de Santa Maria. Foram utilizados três volumes de substratos e três diferentes tamanhos de tubetes $\left(50,110\right.$ e $\left.180 \mathrm{~cm}^{3}\right)$ e três composições de substrato comercial, a base de turfa (Carolina Soil ${ }^{\circledR}$ ), acrescido de casca de arroz carbonizada (CAC) - (Turfa 100\%; Turfa 80\% + 20\% CAC e Turfa 60\% + 40\% CAC). Para a análise dos dados foi utilizado delineamento inteiramente casualizado (DIC) em esquema bifatorial com quatro repetições por tratamento. A análise dos dados foi feita através do teste de Tukey a $5 \%$. Os resultados do experimento demonstram que recipientes maiores $\left(180 \mathrm{~cm}^{3}\right)$ seriam os mais indicados para produção de Luehea divaricata, assim como a combinação de turfa $100 \%$ como substrato base. A espécie pode ser transplantada a campo em torno dos 150 dias após o semeio.
\end{abstract}

PALAVRAS-CHAVE: características morfológicas, espécie nativa; experimento bifatorial; 


\title{
SEEDLING GROWTH AÇOITA-CAVALO (Luehea divaricata Mart.) UNDER INFLUENCE OF DIFFERENT SUBSTRATES AND CONTAINERS IN NURSERY
}

\begin{abstract}
Luehea divaricata is a native species widely distributed in Brazil, widely used as a medicinal plant and reforestation programs. In order to provide quality seedlings for these projects, this research aims to study the development of Luehea divaricata in different substrates and recipients. Arrays tree seeds were collected in the city of Silveira Martins, and the experiment was conducted in a greenhouse at the Federal University of Santa Maria. They used three volumes of substrates and three different tube sizes (50, 110 and $180 \mathrm{~cm}^{3}$ ) and three commercial substrate compositions, peat-based (Carolina Soil囚) plus carbonized rice husk (CAC) - (100 Peat \%, 80\% peat $+20 \%$ and CAC $60 \%$ peat $+40 \%$ CAC). For data analysis was used completely randomized design (CRD) in a factorial scheme with four replicates per treatment. Data analysis was performed using 5\% Tukey test. The experimental results demonstrate that larger containers $\left(180 \mathrm{~cm}^{3}\right)$ would be the most suitable for production Luehea divaricata, as well as the combination of peat $100 \%$ as a base substrate. The species can be transplanted into the field around 150 days after sowing.
\end{abstract}

KEYWORDS: native species; factorial experiment; Morphological characteristics.

\section{INTRODUÇÃO}

Luehea divaricata, conhecida popularmente como Açoita-cavalo, pertence à família Malvaceae e possui ampla distribuição nos estados brasileiros, ocorrendo do rio Grande do Sul até Minas Gerais. Espécie comum na vegetação secundária, podendo ser encontra no bioma mata atlântica, cerrado, caatinga e pampa (CARVALHO, 2008). Dentre seus múltiplos potenciais, destaca-se sua utilização como planta medicinal (BERNARDI-WENZEL et al., 2010), em programas de reflorestamento do norte ao sul do Brasil, ocupando áreas de florestas ripárias e solos drenados (DE CARVALHO et al., 2008).

É uma espécie florestal que vêm sofrendo com as ações antrópicas submetidas às florestas naturais, contribuindo muito para a redução das populações naturais (FLÔRES, 2011). No entanto, a conscientização da população em relação aos problemas ambientais e às exigências da política ambiental, tem levado a uma crescente demanda por espécies florestais nativas (BORTOLINI et al., 2012), assim como do conhecimento em procedimentos relacionados à produção de mudas de espécies arbóreas.

A produção de mudas florestais vem se tornando uma atividade de grande importância para a recomposição de áreas degradadas, auxiliando na retomada do equilíbrio natural (OLIVEIRA et al., 2014). GASPARIN et al. (2014) mencionam que o estabelecimento de plantios florestais, seja para fins comerciais ou restauração, depende de uma série de fatores, sendo a qualidade das mudas ponto fundamental para o sucesso inicial de um projeto. Assim, faz-se de grande importância a definição de técnicas e protocolos que melhor se adequem à produção de nativas, a fim de se obter mudas de qualidade superior em um menor espaço de tempo.

Quando se trabalha com produção de mudas, principalmente àquelas de estágio sucessional tardia à clímax é a questão do crescimento lento o que torna imprescindível a definição de estratégias e elaboração de técnicas que visem à 
produção em menor espaço de tempo (GASPARIN et al. 2014), mantendo a qualidade no processo produtivo.

As mudas produzidas devem apresentar alto padrão de qualidade, para que possam se estabelecer com êxito no local definitivo de plantio (DUARTE et al., 2015), resultando em aumento do percentual de sobrevivência a campo e diminuindo a necessidade de novos replantios (CARNEIRO, 1995).

A utilização de substratos e tamanhos de recipientes adequados pode favorecer a maior sobrevivência das mudas no campo, propiciando maior precocidade no processo produtivo, diminuindo assim os custos de produção. DUMROESE et al. (2011) comprovam que o tipo de recipiente e suas dimensões exercem influências diretas sobre a qualidade e os custos de produção de mudas.

$\mathrm{Na}$ determinação da qualidade das mudas produzidas, podem ser utilizadas variáveis relacionadas à aspectos fisiológicos e morfológicos, determinados física ou visivelmente (STURION \& ANTUNES, 2000). Dentre as características morfológicas, a altura da parte aérea constitui-se como uma variável da predição do crescimento inicial a campo, sendo ainda uma medida do potencial de desempenho das mudas (GOMES et al. 2013). Outra característica morfológica é o diâmetro do coleto, método não destrutivo e de fácil mensuração, importante característica na estimação da sobrevivência (GOMES et al. 2013).

Dessa forma, o presente trabalho tem como objetivo avaliar 0 desenvolvimento da espécie nativa Luehea divaricata em diferentes substratos e recipientes, utilizando como parâmetros avaliativos centrais altura e diâmetro de coleto.

\section{MATERIAL E MÉTODOS}

\section{Local de estudo}

A pesquisa foi conduzida em casa de vegetação, localizada no viveiro florestal da Universidade Federal de Santa Maria (UFSM), município de Santa Maria, região central do RS, nas coordenadas -29.7205 S, -53.7216 O, com altitude de 90 a 95 metros. As sementes coletadas para o experimento foram obtidas no ano de 2010, de árvores matrizes localizadas no distrito de Val Feltrina, município de Silveira Martins, distante cerca de $33 \mathrm{Km}$ do município de Santa Maria, sob as coordenadas 2938'42"S; 5336'53"O, com altitude de 152 metros.

Segundo classificação de Köppen, a região central apresenta clima subtropical, do tipo Cfa, sem estação seca e precipitações bem distribuídas durante 0 ano, com temperaturas entre $3^{\circ} \mathrm{C}$ e $2^{\circ} \mathrm{C}$, nas estações mais frias e mais quentes, respectivamente (MORENO, 1961).

\section{Delineamento experimental}

Foram utilizados três volumes de substratos representado por diferentes tamanhos de tubetes (Tubete 50, Tubete 110 e Tubete $180 \mathrm{~cm}^{3}$ ) e três composições de substrato comercial, a base de turfa (Carolina Soil ${ }^{\circledR}$ ), acrescido de casca de arroz carbonizada (Tabela 1), (CAC) - (Turfa 100\%; Turfa 80\% + 20\% CAC e Turfa $60 \%+$ $40 \%$ CAC). 
TABELA 1.Demonstração do planejamento do experimento com diferentes substratos e tubetes

\begin{tabular}{rrr}
\hline TRATAMENTO & TUBETE & \multicolumn{1}{c}{ SUBSTRATO } \\
\hline T1 S1 & $50 \mathrm{~cm}^{3}$ & Turfa $100 \% ;$ \\
T1 S2 & $50 \mathrm{~cm}^{3}$ & Turfa $+20 \% \mathrm{CAC}$ \\
T1 S3 & $50 \mathrm{~cm}^{3}$ & Turfa $+40 \% \mathrm{CAC}$ \\
& & \\
T2 S1 & $110 \mathrm{~cm}^{3}$ & Turfa $100 \% ;$ \\
T2 S2 & $110 \mathrm{~cm}^{3}$ & Turfa $+20 \%$ CAC \\
T2 S3 & $110 \mathrm{~cm}^{3}$ & Turfa $+40 \% \mathrm{CAC}$ \\
& & \\
T3 S1 & $180 \mathrm{~cm}^{3}$ & Turfa $100 \% ;$ \\
T3 S2 & $180 \mathrm{~cm}^{3}$ & Turfa $+20 \% \mathrm{CAC}$ \\
T3 S3 & $180 \mathrm{~cm}^{3}$ & Turfa $+40 \% \mathrm{CAC}$ \\
\hline
\end{tabular}

O delineamento experimental utilizado foi inteiramente casualizado (DIC) em esquema bifatorial $(3 \times 3)$, com quatro repetições por tratamento, totalizando nove tratamentos e 36 unidades amostrais. A interpretação dos resultados obtidos para a combinação tubete e tipo de substrato, foi feita a análise da variância e teste de Tukey a $5 \%$ de probabilidade de erro, em virtude da natureza qualitativa dos fatores estudados.

Para análise do experimento ao longo de 180 dias a interpretação dos resultados nesta etapa de trabalho baseou-se na análise dos dados ao longo do tempo do experimento $(60,90,120,150$ e 180 dias), para os parâmetros DC, $\mathrm{H} \mathrm{e}$ $H / D$. Sendo um experimento bifatorial $(3 \times 3)$ com parcelas subdivididas no tempo foram analisados, através da ANOVA, as significâncias dos tubetes, substratos e tempo, assim como, a interação entre os fatores.

As análises estatísticas foram realizadas pelo programa computacional Sistema para Análise de Variância - Sisvar ® (FERREIRA, 2000).

\section{Adubação e irrigação}

A adubação de base do substrato foi realizada pela mistura dos adubos comerciais Ourofós ${ }^{\circledR}$ e Sulfamo ${ }^{\circledR}$.

A adubação de cobertura foi feita a partir dos quatros meses após a semeadura aplicado semanalmente a solução a base de Peter's ${ }^{\circledR}$ Professional, fertilizante mineral misto, de composição NPK $9-45-15$. No preparo da solução foram utilizados de $3 \mathrm{~g}$ do produto diluídos em 1 litro de água, aplicando em horários com incidência solar amena.

A irrigação foi realizada através de aspersores, com irrigações programadas, com média de 3,6 mm de água, distribuídos em quatro aplicações diárias.

O plantio da espécie Luehea divaricata, foi realizado no segundo semestre de 2010, mês de agosto, sendo dispostas três sementes por recipiente.

As mudas de Luehea divaricata permaneceram em casa de vegetação por 120 dias, após transferidas para a área de rustificação por um período de 60 dias, com irrigação diária de $16 \mathrm{~mm} /$ dia aplicada quatro vezes ao dia.

\section{Avaliações}

Foi realizada contagens de emergência de plântulas, que apresentaram total abertura dos cotilédones, sendo realizada a cada dois dias até a estabilização. Após 
foi feita a repicagem de plântulas para os recipientes onde não ocorreu a germinação, sendo o transplante realizado somente entre as repetições do mesmo tratamento.

Aos 60 dias, após completada a emergência das plântulas, foi mensurada a altura $(\mathrm{H})$ e o diâmetro do coleto $(\mathrm{DC})$ das mudas, com auxílio régua graduada e o paquímetro digital. Essas medições foram feitas em intervalos de 30 dias até o final do experimento. Manteve-se uma faixa de bordadura de plantas, analisando-se somente as oito centrais.

O encerramento do experimento ocorreu 180 dias após a semeadura, utilizando-se oito plantas centrais por repetição para a obtenção dos dados de diâmetro do coleto (DC - $\mathrm{mm})$ e altura $(\mathrm{H}-\mathrm{cm})$. Para realização dos testes destrutivos utilizaram-se duas plantas por repetição avaliando-se os seguintes parâmetros: massa seca do sistema radicular (MSSR), massa seca da parte aérea (MSPA), massa seca total (MST) e o Índice de Qualidade de Dickson (IQD) (DICKSON et al., 1960).

\section{RESULTADOS E DISCUSSÕES}

O início da emergência das plântulas na casa de vegetação começou aos 17 dias após o semeio, estendendo-se até 42 dias de instalação do experimento. Segundo LORENZI (1998) a emergência de novas plântulas de Luehea divaricata ocorre no período de 20 a 40 dias. A repicagem foi realizada após a emergência se tornar constante, para os casos onde nenhuma semente germinou.

$\mathrm{Na}$ análise bifatorial tubete $\mathrm{x}$ substrato ao longo do tempo de avaliação, observou-se que não houve interação significativa para a variável estudada. $O$ mesmo caso foi verificado quando analisada a fonte de variação substrato $\mathrm{x}$ tempo, não havendo interação significativa entre as médias ao longo do tempo de avaliação do experimento.

Quanto ao parâmetro diâmetro do coleto, ao longo de 180 dias (Tabela 2) observa-se que as maiores médias de crescimento são obtidas quando ocorre a combinação do maior recipiente $\left(180 \mathrm{~cm}^{3}\right)$ com o substrato 1 (Turfa 100\%).

TABELA 2.Médias de DC $(\mathrm{mm})$ de mudas de Luehea divaricata avaliadas ao longo do tempo, onde o substrato 1 corresponde a (Turfa $100 \%$ ), substrato 2 (Turfa $80 \%+20 \%$ CAC) e substrato 3 (Turfa $60 \%+40 \%$ CAC)

\begin{tabular}{|c|c|c|c|c|c|c|c|c|c|}
\hline \multicolumn{10}{|c|}{ Diâmetro do coleto (mm) } \\
\hline \multirow{3}{*}{$\begin{array}{l}\text { Tubete } \\
\left(\mathrm{cm}^{3}\right)\end{array}$} & & 50 & & \multicolumn{3}{|c|}{110} & \multicolumn{3}{|c|}{180} \\
\hline & \multicolumn{9}{|c|}{ Substrato } \\
\hline & 1 & 2 & 3 & 1 & 2 & 3 & 1 & 2 & 3 \\
\hline $\begin{array}{l}\text { Média } \\
\text { geral }\end{array}$ & $\begin{array}{l}2,67 \\
\text { bC }^{*}\end{array}$ & $\begin{array}{l}3,07 \\
\text { AC }\end{array}$ & $\begin{array}{l}2,94 \\
\mathrm{AbC}\end{array}$ & $\begin{array}{c}3,88 \\
\text { aB }\end{array}$ & $\begin{array}{c}3,78 \\
\mathrm{aB}\end{array}$ & $\begin{array}{c}3,72 \\
\text { aB }\end{array}$ & $\begin{array}{c}4,62 \\
\text { aA }\end{array}$ & $\begin{array}{c}4,65 \\
\text { BA }\end{array}$ & $\begin{array}{r}4,31 \\
\text { cA }\end{array}$ \\
\hline
\end{tabular}


Mudas com diâmetro de coleto superior associam-se a um desenvolvimento mais acentuado da parte aérea e, em especial, do sistema radicular, favorecendo a sobrevivência e o desenvolvimento das mudas após o plantio (GRAVE et al., 2007). SCALON et al. (2002) observaram, no crescimento inicial de mudas de espécies florestais nativas, a importância do diâmetro do coleto como característica valiosa na avaliação do potencial da planta para a sobrevivência e crescimento após o plantio.

$\mathrm{Na}$ Tabela 3, observa-se que para o recipiente de $50 \mathrm{~cm}^{3}$ não houve diferença significativa no diâmetro das plantas a partir dos 120 dias em viveiro, havendo dessa forma maior incremento em diâmetro na fase inicial de avaliação (60 e 90 dias), enquanto havia espaço para seu crescimento, considerando a característica de rápido crescimento da espécie. Para o tubete $110 \mathrm{~cm}^{3} \circ$ comportamento foi semelhante, apresentando diferenças de diâmetro durante o período de 60 e 90 dias. Os maiores valores foram verificados quando utilizado o tubete $180 \mathrm{~cm}^{3}(5,85$ $\mathrm{mm}$ ), não havendo incremento significativo a partir dos 150 dias de avaliação.

TABELA 3 - Valores médios do DC ( $\mathrm{mm}$ ) de mudas de Luehea divaricata, aos 60, 90, 120, 150 e 180 dias após a semeadura, em função de diferentes tubetes.

\begin{tabular}{crrrr}
\hline \multicolumn{5}{c}{ Diâmetro do coleto $(\mathbf{m m})$} \\
\hline TUBETE $(\mathbf{c m} 3)$ \\
\hline $\mathbf{5 0}$ & $\mathbf{1 1 0}$ & $\mathbf{1 8 0}$ & Média geral \\
\hline $\mathbf{5 0}$ & $1,95 \mathbf{~}$ & $2,18 \mathbf{c}$ & $2,17 \mathbf{~}$ & 2,10 \\
$\mathbf{1 2 0}$ & $2,67 \mathbf{~ b}$ & $3,34 \mathbf{b}$ & $3,74 \mathbf{~}$ & 3,26 \\
$\mathbf{1 5 0}$ & $3,18 \mathbf{a}$ & $4,23 \mathbf{a}$ & $5,17 \mathbf{~ b}$ & 4,19 \\
$\mathbf{1 8 0}$ & $3,32 \mathbf{a}$ & $4,55 \mathbf{a}$ & $5,70 \mathbf{a}$ & 4,53 \\
Média geral & $3,36 \mathbf{a}$ & $4,66 \mathbf{a}$ & $5,85 \mathbf{a}$ & 4,63 \\
\hline
\end{tabular}

*Médias com a mesma letra na coluna não diferem entre si pelo teste de Tukey a 5\%.

Ainda com relação ao diâmetro do coleto, pode-se observar na Figura 1, o crescimento ao longo dos 180 dias de avaliação. Observa-se que com relação a variável coleto, as mudas de recipientes maiores apresentaram melhores resultados, sendo o recipiente de $180 \mathrm{~cm}^{3}$ aquele que proporcionou melhores resultados no desenvolvimento do coleto. $\mathrm{O}$ recipiente de $50 \mathrm{~cm}^{3}$ apresentou médias inferiores de crescimento do coleto, se comparado com o coleto das plantas dispostas nos recipientes de 110 e $180 \mathrm{~cm}^{3}$. Recipientes com menores dimensões podem ocasionar menor desenvolvimento, das plantas, isso porque os nutrientes são limitantes ou esgotados em menor tempo em recipientes menores do que para os maiores (BARDIVIESSO et al. 2011).

Mudas com diâmetro do colo pequeno podem apresentar problemas relacionados com sustentação da planta, podendo ocasionar o tombamento, com posterior mortalidade ou deformações que comprometem o valor silvicultural final das plantas (CUNHA et al. 2005).

No entanto, não se pode afirmar que recipientes menores produzem indivíduos com coleto menor, pois se depende de vários fatores, dentre estes o tipo de espécie, substrato, dentre outros. QUIROZ et al. (2014) em trabalho sobre Acacia dealbata em viveiro e no campo em sequeiro da Região de Biobío, Chile constataram que a tendência final observada em sua pesquisa resultou em menores 
incrementos das plantas em recipientes maiores, e maiores incrementos em recipientes menores.

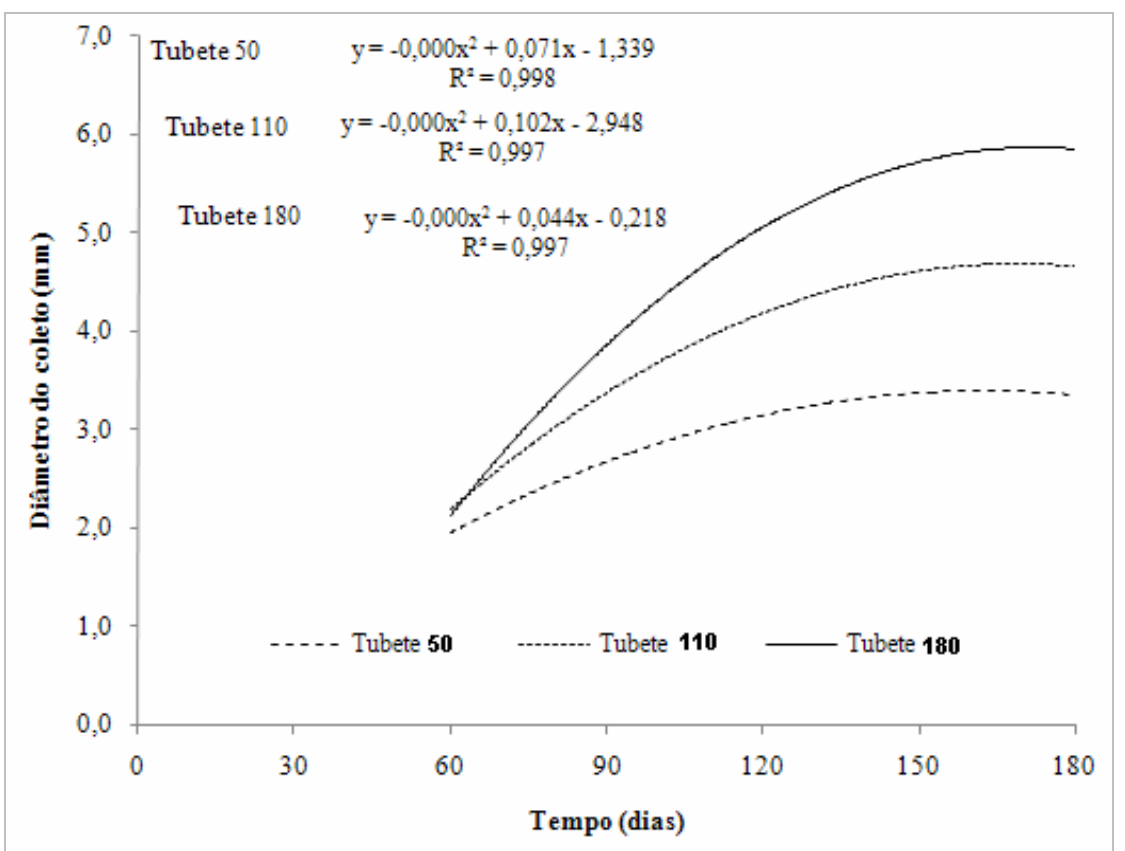

FIGURA 1- Diâmetro do coleto ao longo dos 180 dias de avaliação, nos três diferentes tipos de tubetes $\left(50 \mathrm{~cm}^{3}, 110 \mathrm{~cm}^{3}, 180 \mathrm{~cm}^{3}\right)$.

Com relação à variável altura, na interação tubete $x$ substrato (Tabela 4) observa-se que as melhores médias foram obtidas quando foi realizada a associação do tubete de $180 \mathrm{~cm}^{3} \mathrm{com}$ o substrato 1 (turfa 100\%), com média de altura de $21,42 \mathrm{~cm}$ e substrato 3 (Turfa $60 \%+40 \%$ CAC) e tubete $3\left(180 \mathrm{~cm}^{3}\right) \mathrm{com}$ média de $14,71 \mathrm{~cm}$.

TABELA 4 - Médias de altura $(\mathrm{H})(\mathrm{cm})$ na interação substrato x recipiente ao longo do tempo, onde substrato 1 corresponde a (Turfa 100\%), substrato 2 (Turfa $80 \%+20 \%$ CAC) e substrato 3 (Turfa $60 \%+40 \%$ CAC).

\begin{tabular}{|c|c|c|c|c|c|c|c|c|c|}
\hline \multicolumn{10}{|c|}{ Altura (cm) } \\
\hline \multirow[t]{3}{*}{ Tubete $\left(\mathrm{cm}^{3}\right)$} & & 50 & & & 110 & & & 180 & \\
\hline & \multicolumn{9}{|c|}{ Substrato } \\
\hline & 1 & 2 & 3 & 1 & 2 & 3 & 1 & 2 & 3 \\
\hline Média geral & $\begin{array}{r}7,65 \\
\text { bC }\end{array}$ & $\begin{array}{l}9,02 \\
\text { abC }\end{array}$ & $\begin{array}{r}9,33 \\
\text { aB }\end{array}$ & $\begin{array}{r}13,63 \\
a B\end{array}$ & $\begin{array}{r}14,88 \\
a B\end{array}$ & $\begin{array}{r}14,71 \\
\text { aA }\end{array}$ & $\begin{array}{r}21,42 \\
\text { aA }\end{array}$ & $\begin{array}{r}19,51 \\
\text { bA }\end{array}$ & $\begin{array}{r}15,92 \\
\text { CA }\end{array}$ \\
\hline
\end{tabular}

${ }^{*}$ As médias seguidas da mesma letra minúscula na linha e da mesma letra maiúscula na coluna não diferem entre si, estatisticamente, pelo teste de Tukey a $5 \%$ de probabilidade.

Ainda com relação à variável altura, são apresentados na Tabela 5, os valores médios da altura das mudas de Luehea divaricata em cada período de avaliação. Desse modo, se comparadas as médias de crescimento, pode-se verificar que para ambos os tratamentos, existe um crescimento acentuado nos primeiros 120 dias, 
após o semeio. Após esse período as médias apresentam pouca variação, indicativo de que este seria o período máximo de permanência destas plantas em tubete, sendo necessário seu plantio a campo.

TABELA 5 -Valores médios da altura $(\mathrm{H})(\mathrm{cm})$ de mudas de Luehea divaricata, aos 60, 90, 120, 150 e 180 dias após a semeadura, em função de diferentes tubetes.

\begin{tabular}{|c|c|c|c|c|}
\hline \multicolumn{5}{|c|}{ Altura (cm) } \\
\hline \multirow[b]{2}{*}{ TEMPO } & \multicolumn{3}{|c|}{ TUBETE $\left(\mathrm{cm}^{3}\right)$} & \multirow[b]{2}{*}{ Média geral } \\
\hline & 50 & 110 & 180 & \\
\hline 60 & $6,01 \mathrm{c}$ & $8,19 \mathrm{c}$ & $8,42 \mathrm{c}$ & 7,54 \\
\hline 90 & $8,15 \mathbf{b}$ & $13,00 \mathbf{b}$ & $16,71 \mathbf{b}$ & 12,62 \\
\hline 120 & $9,49 \mathbf{a}$ & $16,38 \mathbf{a}$ & $22,19 \mathbf{a}$ & 16,02 \\
\hline 150 & $9,77 \mathbf{a}$ & $17,17 \mathbf{a}$ & $23,39 \mathbf{a}$ & 16,78 \\
\hline 180 & $9,92 \mathbf{a}$ & $17,29 \mathbf{a}$ & 24,05 a & 17,09 \\
\hline Média geral & 8,67 & 14,41 & 18,95 & 14,01 \\
\hline
\end{tabular}

*Médias com a mesma letra na coluna não diferem entre si pelo teste de Tukey a $5 \%$.

Os resultados demonstrados na Tabela 5, podem ser visualizados na Figura 2 , onde se observa uma estabilização na curva de crescimento.

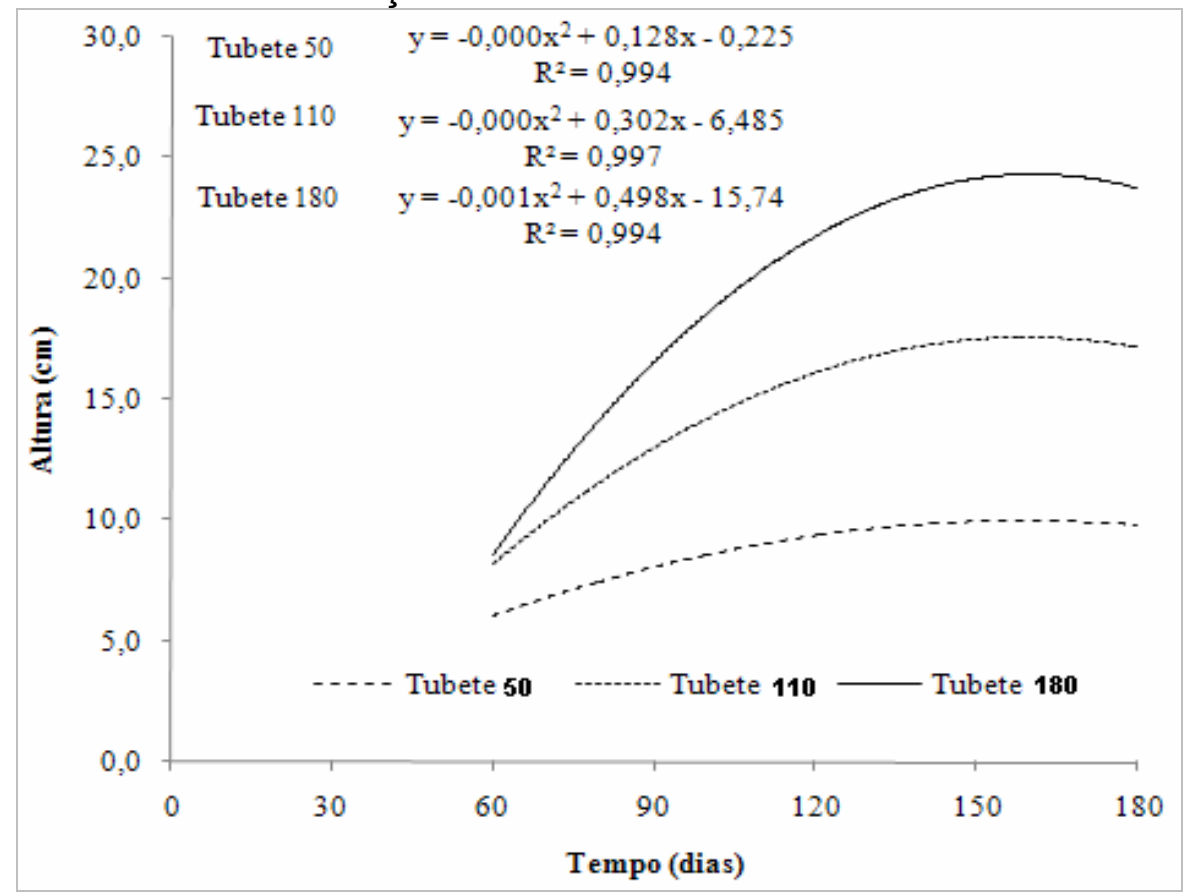

FIGURA 2- Curva de crescimento em altura da espécie Luehea divaricata ao longo dos 180 dias de experimento

Se observado a relação $H / D$ (Tabela 6) verifica-se novamente que a melhor combinação de tratamentos seria a utilização do tubete de $180 \mathrm{~cm}^{3} \mathrm{com}$ o substrato 1 (turfa 100\%). A combinação substrato 3 (Turfa $+40 \%$ CAC) e tubete $110 \mathrm{~cm}^{3}$ apresentou o mesmo comportamento que a combinação substrato 1 (Turfa $100 \%$ ) e tubete $180 \mathrm{~cm}^{3}$, com média de 3,98, em comparação à 4,57 (tubete $180 \mathrm{~cm}^{3} \mathrm{e}$ substrato 1). 
Comportamento semelhante pode ser observado na pesquisa de FERRAZ \& ENGEL (2011) onde se observou que até os 170 dias, as mudas produzidas no tubete de $300 \mathrm{~cm}^{3}$ apresentaram tanto altura quanto diâmetro do colo significativamente superior aos das mudas produzidas nos tubetes de menores volumes (110 e $150 \mathrm{~cm}^{3}$ ). Segundo CUNHA (2005), mudas com diâmetro do colo pequeno e grandes alturas podem ser consideradas de qualidade inferior silviculturalmente se comparadas àquelas de menores alturas e com maior diâmetro do colo.

TABELA 6 - Médias da relação H/D na interação substrato x recipiente ao longo do tempo, onde substrato 1 corresponde a (Turfa 100\%), substrato 2 (Turfa $+20 \%$ CAC) e substrato 3 (Turfa $+40 \%$ CAC) .

\section{Relação H/D}

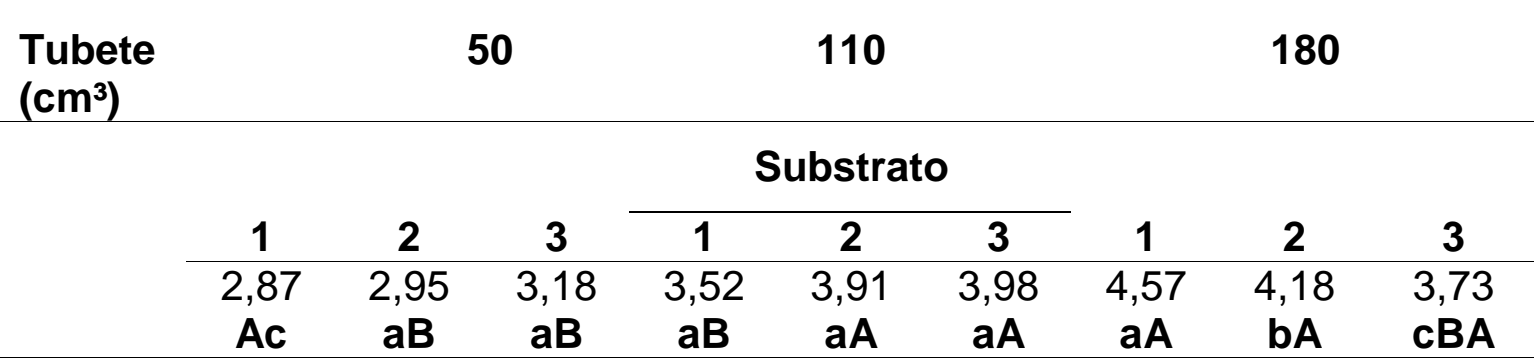

${ }^{\star}$ As médias seguidas da mesma letra minúscula na linha e da mesma letra maiúscula na coluna não diferem entre si, estatisticamente, pelo teste de Tukey a $5 \%$ de probabilidade.

\section{Análise final, aos 180 dias:}

Aos 180 dias após a semeadura, as mudas de Luehea divaricata apresentaram diferença significativa no crescimento entre os diferentes tubetes para as variáveis diâmetro do colo $(D C)$, altura $(H)$, relação $H / D$, massa seca da parte aérea (MSPA), massa seca do sistema radicular (MSSR), massa seca total (MST) e Índice de qualidade de Dickson (IQD). Observou-se que as mudas produzidas no recipiente maior $\left(180 \mathrm{~cm}^{3}\right)$ possuem médias superiores se comparados aos recipientes de $110 \mathrm{~cm}^{3}$ e $50 \mathrm{~cm}^{3}$ para todas as variáveis analisadas (Tabela 7).

SANTOS et al. (2000) em experimento com a espécie Chryptomeria japonica, utilizando tubetes de $50 \mathrm{~cm}^{3}, 120 \mathrm{~cm}^{3}$ e $240 \mathrm{~cm}^{3}$ constataram que os valores de todas as variáveis analisadas (altura, diâmetro do colo, massa seca da raiz e massa seca da parte aérea) aumentam com o tamanho de tubete utilizado.

TABELA 7 - Valores médios do diâmetro do coleto $(D C)$, altura $(H)$, relação altura/diâmetro $(\mathrm{H} / \mathrm{D})$, massa seca da parte aérea (MSPA), massa seca do sistema radicular (MSSR), massa seca total (MST) e índice de qualidade de Dickson (IQD) aos 180 dias após a semeadura, em função de diferentes tamanhos de tubetes.

\begin{tabular}{crrrrrrr}
\hline $\begin{array}{c}\text { Tubete } \\
\left(\mathbf{c m}^{3}\right)\end{array}$ & $\mathbf{D C}(\mathbf{m m})$ & $\mathbf{H}(\mathbf{c m})$ & $\mathbf{H} / \mathbf{D}$ & $\begin{array}{c}\text { MSPA } \\
\mathbf{( g )}\end{array}$ & MSSR $(\mathbf{g})$ & MST $(\mathbf{g})$ & IQD \\
\hline $\mathbf{1 8 0}$ & $5,85 \mathbf{a}^{*}$ & $24,05 \mathbf{a}$ & $4,11 \mathbf{a}$ & $2,12 \mathbf{a}$ & $1,92 \mathbf{a}$ & $4,04 \mathbf{a}$ & $0,77 \mathbf{~ a}$ \\
$\mathbf{1 1 0}$ & $4,67 \mathbf{b}$ & $17,29 \mathbf{b}$ & $3,71 \mathbf{b}$ & $1,21 \mathbf{b}$ & $1,44 \mathbf{b}$ & $2,65 \mathbf{b}$ & $0,59 \mathbf{b}$ \\
$\mathbf{5 0}$ & $3,36 \mathbf{c}$ & $9,92 \mathbf{c}$ & $2,95 \mathbf{c}$ & $0,50 \mathbf{c}$ & $0,66 \mathbf{c}$ & $1,16 \mathbf{c}$ & $0,31 \mathbf{c}$ \\
\hline $\mathbf{C V}(\%)$ & 5,71 & 4,19 & 5,33 & 12,02 & 13,71 & 11,79 & 13,36 \\
\hline
\end{tabular}


Na Figura 3 pode-se observar o sistema radicular das plantas dos tratamentos com Turfa $+20 \%$ CAC e tubete de $180 \mathrm{~cm}^{3}$ (T3S2); Turfa $+20 \%$ CAC e tubete 110 $\mathrm{cm}^{3}$ (T2S2) e Turfa $+20 \%$ CAC com recipiente de $50 \mathrm{~cm}^{3}$ (T1S2).

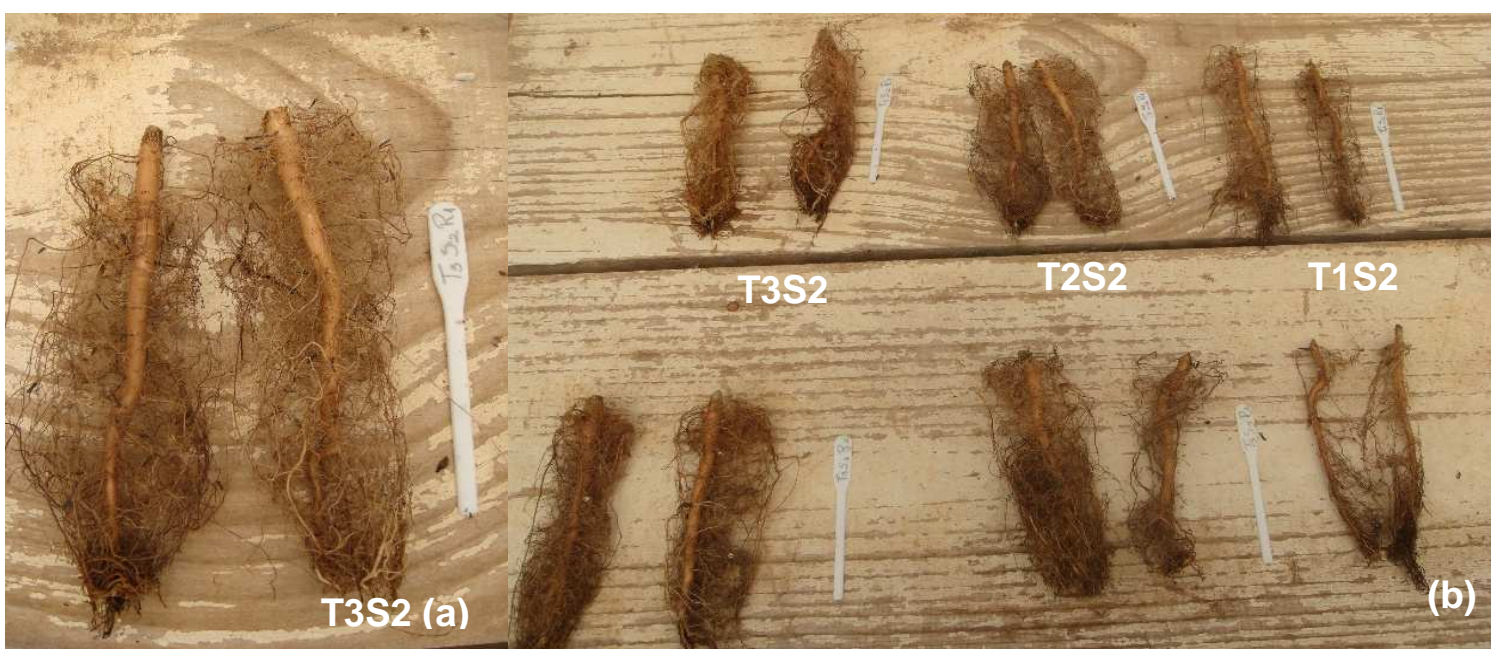

FIGURA 3- Imagens das raízes de Luehea divaricata (a) e (b), após preparo da amostra para obtenção de peso seco radicial.

Com relação aos substratos utilizados (Tabela 8 ) observa-se que não houve diferença significativa para diâmetro do coleto (DC), massa seca da parte aérea (MSPA), massa seca do sistema radicular (MSSR), massa seca total (MST) e Índice de qualidade de Dickson. GRAVE et al. (2007) ao analisarem a massa seca das raízes das mudas de Luehea divaricata, obtida no substrato casca de arroz carbonizada (CAC) e turfa observou que esta foi reduzida, não apresentando diferença significativa nas três avaliações realizadas nos substratos testados. Isso evidencia que o desenvolvimento do sistema radicular no substrato com CAC pode dificultar o desenvolvimento das plantas após o plantio.

TABELA 8 - Valores médios do diâmetro do coleto (DC), massa seca da parte aérea (MSPA), massa seca do sistema radicular (MSSR), massa seca total (MST) e índice de qualidade de Dickson (IQD) de mudas de Luehea divaricata, aos 180 dias após a semeadura, em função de diferentes substratos.

\begin{tabular}{crrrrr}
\hline Substrato & DC $(\mathbf{m m})$ & \multicolumn{1}{c}{ MSPA $(\mathbf{g})$} & MSSR $(\mathbf{g})$ & MST (g) & IQD \\
\hline Turfa $\mathbf{1 0 0} \%$ & 4,54 & 1,36 & 1,36 & 2,72 & 0,56 \\
Turfa $+\mathbf{2 0} \%$ CAC & 4,69 & 1,24 & 1,32 & 2,56 & 0,54 \\
Turfa $+\mathbf{4 0} \%$ CAC & 4,65 & 1,23 & 1,35 & 2,58 & 0,57 \\
\hline CV (\%) & 4,47 & 12,00 & 9,76 & 10,48 & 9,76 \\
\hline
\end{tabular}

${ }^{*}$ Médias não diferem entre si pelo teste $\mathrm{F}$ (ANOVA).

Quando analisada a interação entre os fatores Tubete $x$ Substrato, observouse que houve interação significativa para os parâmetros altura e relação H/D. A partir desta constatação buscou-se determinar qual a combinação de substrato e tubete que apresentasse melhor média para essas variáveis. Na Tabela 9 observa-se que a 
maior média em altura $(27,46 \mathrm{~cm})$ acontece quando ocorre a combinação do substrato (1) Carolina Soil ${ }^{\circledR} 100 \%$ e o tubete de $180 \mathrm{~cm}^{3}$.

TABELA 9 - Valores médios de altura $(\mathrm{H})$ de mudas de Luehea divaricata, aos 180 dias após a semeadura, em função da combinação de diferentes substratos e tubetes.

\begin{tabular}{|c|c|c|c|c|}
\hline \multirow[b]{3}{*}{$\begin{array}{l}\text { Tubete } \\
\left(\mathrm{cm}^{3}\right)\end{array}$} & \multicolumn{3}{|c|}{ Altura (cm) } & \multirow[b]{3}{*}{$\begin{array}{l}\text { Média } \\
\text { geral }\end{array}$} \\
\hline & \multicolumn{3}{|c|}{ Substrato } & \\
\hline & Turfa $100 \%$ & Turfa $+20 \%$ CAC & Turfa $+40 \%$ CAC & \\
\hline 50 & $8,57 \mathrm{bC}$ & $10,20 a b c$ & $10,99 \mathrm{aB}$ & 9,93 \\
\hline 110 & $16,12 \mathrm{aB}$ & $17,87 \mathbf{a B}$ & $17,87 \mathbf{a A}$ & 17,29 \\
\hline 180 & 27,46 aA & 24,16 bA & 20,52 cA & 24,05 \\
\hline $\begin{array}{l}\text { Média } \\
\text { geral }\end{array}$ & 17,39 & 17,42 & 16,47 & 17,09 \\
\hline
\end{tabular}

${ }^{\star}$ As médias seguidas da mesma letra minúscula na linha e da mesma letra maiúscula na coluna não diferem entre si, estatisticamente, pelo teste de Tukey a $5 \%$ de probabilidade.

A seguir pode ser visualizado na Figura 4 o estágio final de desenvolvimento das mudas de Luehea divaricata, 180 dias após o semeio.

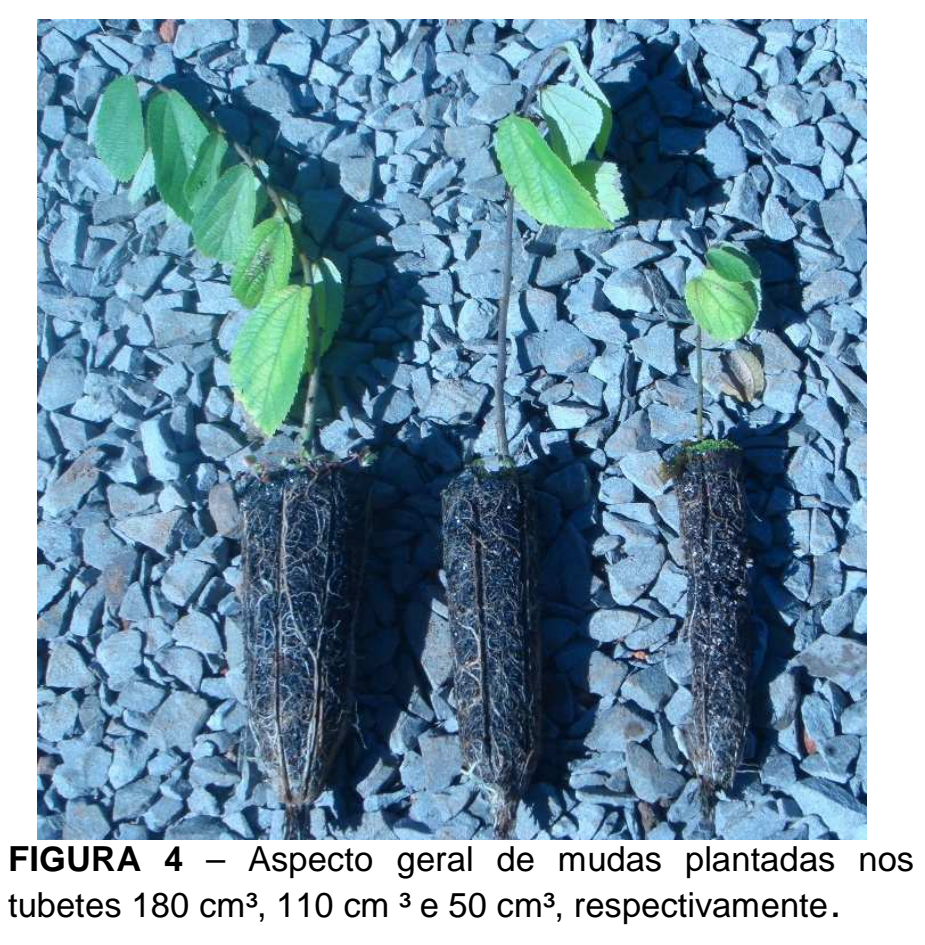

Com a relação ao parâmetro H/D (Tabela 10) foi verificado que as maiores médias $(4,69)$ foram encontradas quando ocorreu a combinação tubete $180 \mathrm{~cm}^{3} \mathrm{e}$ substrato turfa $100 \%$. BALDIN et al. (2015) em estudo com a espécie nativa Paraptadenia rigida, também observaram que as maiores médias para a espécie, estava relacionada com maior volume de substrato e consequentemente menor restrição radicular imposta às plântulas. Ainda segundo os autores menores ENCICLOPÉDIA BIOSFERA, Centro Científico Conhecer - Goiânia, v.11 n.22; p.819 2015 
dimensões de recipiente $\left(50 \mathrm{~cm}^{3}\right)$ seriam limitantes para o crescimento das plantas, acarretando em mudas com qualidade inferior para o plantio em condições de campo. Recipientes de maior tamanho proporcionam a redução do tempo de produção das mudas em viveiro e a obtenção de mudas de melhor qualidade (CAIXETA et al., 2013).

TABELA 10-Valores médios da relação H/D de mudas de Luehea divaricata, aos 180 dias após a semeadura, em função da combinação de diferentes substratos e tubetes.

\begin{tabular}{crrrr}
\hline \multicolumn{5}{c}{ Relação H/D } \\
\hline \multirow{2}{*}{$\begin{array}{c}\text { Tubete } \\
\left(\mathbf{( m}^{\mathbf{3}}\right)\end{array}$} & Turfa $\mathbf{1 0 0} \%$ & Turfa + 20\% CAC & Turfa + $\mathbf{4 0 \%}$ CAC & $\begin{array}{c}\text { Média } \\
\text { geral }\end{array}$ \\
\cline { 2 - 4 } $\mathbf{5 0}$ & 2,79 a C & 2,89 a B & 3,15 a A & 2,95 \\
$\mathbf{1 1 0}$ & 3,42 a B & 3,89 a A & 3,82 a A & 3,71 \\
$\mathbf{1 8 0}$ & 4,69 a A & 4,07 b A & 3,56 c A & 4,11 \\
\hline Média & 3,64 & 3,62 & 3,51 & 3,59 \\
geral & & &
\end{tabular}

${ }^{*}$ As médias seguidas da mesma letra minúscula na linha e da mesma letra maiúscula na coluna não diferem entre si, estatisticamente, pelo teste de Tukey a $5 \%$ de probabilidade.

\section{CONCLUSÃO}

O recipiente de $180 \mathrm{~cm}^{3}$ resultou em plantas com características morfológicas superiores, sendo o mais indicado para a produção de mudas de Luehea divaricata. Quanto ao substrato, a composição turfa $100 \%$, sem a adição de casca de arroz carbonizada, demonstrou ser superior para os parâmetros analisados, influenciando positivamente no crescimento das plantas. Conclui-se também que para a espécie Luehea divaricata, em termos regionais, 150 dias após a semeadura seriam suficientes para o desenvolvimento destas em viveiro, podendo após esse período já serem plantadas a campo.

\section{REFERÊNCIAS}

BALDIN, T., CONTE, B., DENARDI, L., DE MORAES, R., SALDANHA, C. W. Crescimento de mudas de angico-vermelho em diferentes volumes de substratos. Pesquisa florestal brasileira, Colombo, v. 35, n. 82, p. 129-133, abr./jun. 2015. Doi: 10.4336/2015.pfb.35.82.829.

BARDIVIESSO, D. M., MARUYAMA, W, I., DOS REIS, L. L., MODESTO, J. H., REZENDE, W. E., Diferentes substratos e recipientes na produção de mudas de guabiroba (Campomanesia pubescens O.Berg). Revista Científica Eletrônica de Agronomia, Garça, v.18, n.1, p. 52-59, jun, 2011.

BERNARDI-WENZEL, J. GARCíA, A., CELSO FILHO J. R., PRIOLI, A. J., PAMPHILE, J. A. Evaluation of foliar fungal endophyte diversity and colonization of medicinal planta Luehea divaricata (Martius et Zuccarini). Biological Researches, v.43 n.4, Santiago, 2010. <http://dx.doi.org/10.4067/S0716-97602010000400001> doi: $10.4067 / S 0716-97602010000400001$. 
BORTOLINI, M. F., KOEHLER, H, S., ZUFFELLATO-RIBAS, K. C., FORTES, A. M. T. Crescimento de mudas de Gleditschia amorphoides Taub. Produzidas em diferentes substratos. Ciência Florestal, Santa Maria, v. 22, n. 1, p. 35-46, jan.-mar, 2012. <http://dx.doi.org/10.5902/198050985077> doi: 10.5902/198050985077.

CAIXETA, A. F. B., REIS, J. M. R., RODRIGUES, J. F. Produção de mudas de jatobá em diferentes dimensões de recipientes e composições de substratos. Revista Agrotecnologia, Anápolis, v. 4, n. 1, p. 46-57, 2013. ISSN 2179-5959.

CARVALHO, P. E. Espécies arbóreas brasileiras. Brasília, DF: Embrapa Informação Tecnológica; COLOMBO, PR: Embrapa Florestas, 2008.

CARNEIRO, J. G. A. Produção e controle de qualidade de mudas florestais. Curitiba: UFPR/FUPEF; Campos: UENF, 1995. 451p.

CUNHA, A. O. BRUNO, R. DE. L. A., DA SILVA, J. A. L., DE SOUZA, V. C. Efeitos de substratos e das dimensões dos recipientes na qualidade das mudas de Tabebuia impetiginosa (Mart. Ex D.C.) Standl. Revista Árvore, v.29 n.4 Viçosa, 2005. http://dx.doi.org/10.1590/S0100-67622005000400002 doi: 10.1590/S0100-67622005000400002.

DUARTE, M. L. DE PAIVA, H. N., ALVES, M. O., DE FREITAS, A. F., MAIA, F. F., GOULART, L. M. L. Crescimento e qualidade de mudas de vinhático (Platymenia foliolosa Benth.) em resposta à adubação com potássio e enxofre. Ciência Florestal, Santa Maria, v. 25, n. 1, p. 221-229, jan.-mar., 2015. <http://www.redalyc.org/articulo.oa? $\mathrm{id}=53438248021>$ doi: 53438248021 .

DE CARVALHO, M. C.C.G. DA SILVA, D. C. G., MEDRI, M. E., RUAS E. A., RUAS, C. F. Flooding tolerance and genetic diversity in populations of Luehea divaricata. Biologia Plantarum, Volume 52, Issue 4, pp 771-774, 2008.

DICKSON, A. FOLHA, A. L., HOSNER, J. F. Quality appraisal of white spruce and white pine seedling stock in nurseries. Forest Chronicle, v.36, p.10-13, 1960. $<10,5558$ / tfc36010-1 > doi: 10,5558 / tfc36010-1

DUMROESE, R. K., DAVIS, A. S., JACOBS, D. F. Nursery response of Acacia koa seedlings to container size, irrigation method, and fertilization rate. Journal of Plant Nutrition, v. 34, p. 877-887, 2011.

FERRAZ, A. V., ENGEL, V. L. Efeito do tamanho de tubetes na qualidade de mudas de Jatobá (Hymenaea courbaril L. var.stillbocarpa (Hayne) Lee et Lang.), Ipê-amarelo (Tabebuia chrysotricha (Mart. ex DC.) Sandl.) e Guarucaia (Parapiptadenia rigida (Benth.) Brenan). Revista Árvore, vol.35 no.3 Viçosa May/June 2011. <http://dx.doi.org/10.1590/S0100-67622011000300005> doi: 10.1590/S010067622011000300005.

FLÔRES, A. V. Estabelecimento e multiplicação in vitro de Luehea divaricata Mart. \& Zucc. Ciência Florestal, Santa Maria, v. 21, n. 1, p. 175-182, jan.mar., 2011. 
FRANCISCO, M. G. S., BARDIVIESSO, D. M., TOST, M. DA. Composição de substratos e tamanho de recipientes na produção e qualidade das mudas de maracujazeiro 'amarelo'. Ciência e agrotecnologia vol. 34 no.3, Lavras May/June $2010 . \quad<$ <ttp://dx.doi.org/10.1590/S141370542010000300009> doi: 10.1590/S1413-70542010000300009

FERREIRA, D.F. Análise estatística por meio do SISVAR (Sistema para Análise de Variância) para Windows versão 4.0. In: REUNIÃO ANUAL DA REGIÃO BRASILEIRA DA SOCIEDADE INTERNACIONAL DE BIOMETRIA, 45, 2000, São Carlos. Anais... São Carlos: UFSCar, p. 255-258. 2000.

GASPARIN, E. DE AVILA, A. L., ARAUJO, M. M., CARGNELUTTI FILHO, A., DORNELES, D. U., FOLTZ, D. R. B. Influência do substrato e do volume de recipiente na qualidade das mudas de Cabralea canjerana (Vell.) Mart. em viveiro e no campo. Ciência Florestal, Santa Maria, v. 24, n. 3, p. 553-563, jul.-set., 2014. $<$ http://dx.doi.org/10.5902/1980509815731> doi: 0.5902/1980509815731.

GRAVE, F., FRANCO, E. T. H.; PACHECO, J. P.; SANTOS, S. R. Crescimento de plantas jovens de Açoita-cavalo em quatro diferentes substratos. Revista Ciência Florestal, Santa Maria, v. 17, 2007.

GOMES' D. R., CALDEIRA' M. V. W., DELARMELINA' W. M., GONÇALVES, E. DE G., TRAZ, P. A. Lodo de esgoto como substrato para produção de mudas de Tectona grandis L. Revista Cerne, vol.19 no.1 Lavras Jan./Mar. 2013. <http://dx.doi.org/10.1590/S0104-77602013000100015> doi: 10.1590/S010477602013000100015

LORENZI, H. Árvores Brasileiras: manual de identificação e cultivo de plantas Árboreas Nativas do Brasil. 2 ed. São Paulo: Plantarum, v.1, p. 234, 1998.

MORENO, J. A. Clima do Rio Grande do Sul. Porto Alegre: Secretaria da Agricultura, 1961. p. 42.

OLIVEIRA, L. S. B. DE ANDRADE, L. A., ALVES, A. S., GONÇALVES, G. S. Substrato e volume de recipiente na produção de mudas de jatobá (Hymenaea courbaril L.). Nativa, Sinop, v. 02, n. 02, p. 103-107, abr./jun. 2014, Pesquisas Agrárias e Ambientais. <http://dx.doi.org/10.14583/2318-7670.v02n02a07> doi: 10.14583/2318-7670.v02n02a07

QUIROZ, I., PINCHEIRA, M. P., HERNÁNDEZ' J. A., GONZÁlEZ, M., GARCíA' E., SOTO, $\mathrm{H}$. Efecto del volumen radicular sobre el crecimiento de Acacia dealbata Link. en vivero y en terreno en el secano de la Región del Biobío, Chile. Revista Árvore, vol.38 no.1 Viçosa jan/fev. 2014.<http://dx.doi.org/10.1590/S0100-

67622014000100015. doi: 10.1590/S0100-67622014000100015

SANTOS, C.B., LONGHI, S. J., HOPPE, J. M., MOSCOVICH, F. A. Efeito do Volume de Tubetes e tipos de Substratos na Qualidade de mudas de Cryptomeria japonica (L.F.) D. Don. Revista Ciência Florestal, v. 10, n. 2, Santa Maria, 2000. 
SCALON, S.P.Q., MUSSURY, R.M.; RIGONI, M.R.; VERALDO, F. Crescimento inicial de mudas de espécies florestais nativas sob diferentes níveis de sombreamento. Revista Árvore, v.26, n.1, p.1-5, 2002.

STURION, J.A., ANTUNES, B.M.A. Produção de Mudas Florestais. In: Galvão, A.P.M. Reflorestamento de Propriedades Rurais para fins de produtivos ambientais, Colombo, p. 38, 2000. 